CLINICAL CASE

\title{
CLINICAL AND SURGICAL ATTITUDE IN A MEN2 SYNDROME CASE WITH MEDULLARY THYROID CARCINOMA RECURRENCE DURING PREGNANCY
}

\author{
Ioana Coțofană ${ }^{1}$, Roxana Roșca ${ }^{1,2}$, Alexandra Mirică ${ }^{1}$, M. Coțofană ${ }^{3}$, D. N. Păduraru ${ }^{2,3}$, R. \\ Mirică $^{5}$, M. Beuran ${ }^{4,2}$, S. Păun ${ }^{4,2}$, Diana Loreta Păun ${ }^{1,2}$ \\ "“C.I. Parhon" National Institute of Endocrinology \\ 2"Carol Davila" University of Medicine and Pharmacy, Bucharest \\ ${ }^{3}$ Bucharest University Emergency Hospital, Romania \\ ${ }^{4}$ Bucharest Emergency Hospital, Romania \\ 5"Sf. Ioan" Clinical Emergency Hospital, Bucharest, Romania \\ Corresponding author: Dan Nicolae Păduraru \\ Phone no. 0040744756443 \\ E-mail: dan.paduraru.nicolae@gmail.com
}

\begin{abstract}
Multiple endocrine neoplasia type 2 is a group of medical disorders associated with tumours of the endocrine system. The tumours may be benign or malignant. They generally occur in the endocrine organs (e.g. thyroid, parathyroid, and adrenals), but may also occur in the endocrine tissues of organs not classically thought of as endocrine. We present the case of a 28-year-old female, with history of MEN2A syndrome confirmed by genetic screening and manifested by bilateral pheochromocytoma, for which she underwent right adrenalectomy in 2009 and left adrenalectomy in 2011, as well as by medullary carcinoma of the thyroid, for which total thyroidectomy was performed in 2009. At present, the patient is under replacement treatment of the thyroid function with LT4 and glucocorticoid and mineralocorticoid replacement therapy with Prednisone and Astonin. Currently, the patient has been periodically presenting herself for clinical and therapeutic endocrinological re-evaluation, in the context of an ongoing pregnancy. During a presentation, in September 2015, the pregnancy being in its 24th week, at ultrasonography, a possible remnant of thyroid tissue was detected, a superior and mediolateral adenopathy, well defined, with some interior calcifications, discretely vascularized, therefore of a suspicious nature and a left supraclavicular small cluster of microcalcifications was also detected. Calcitonin blood level was measured in order to dynamically correlate its evolution with the new ultrasound findings with a significant increase at the current dosing reaching $587.20 \mathrm{pg} / \mathrm{ml}$.
\end{abstract}

Keywords: MEN2A syndrome, pregnancy, calcitonin, recurrent medullary thyroid cancer

\section{Introduction}

Multiple endocrine neoplasia type 2 is a group of medical disorders associated with tumours of the endocrine system. The tumours may be benign or malignant. They generally occur in the endocrine organs (e.g. thyroid, parathyroid, and adrenals), but may also occur in the endocrine tissues of organs not classically thought of as endocrine [1].

MEN2A associates medullary thyroid carcinoma with pheochromocytoma in about 
$20-50 \%$ of cases and with primary hyperparathyroidism in 5-20\% of cases.

In a review of 85 patients, 70 had Men2A and 15 had Men2B. The initial manifestation of MEN2 was medullary thyroid carcinoma in $60 \%$ of patients, medullary thyroid carcinoma synchronous with pheochromocytoma in $34 \%$, and pheochromocytoma alone in $6 \% .72 \%$ had bilateral pheochromocytomas [2].

In the "Guidelines of the American Thyroid Association for the Diagnosis and Management of Thyroid Disease During Pregnancy and Postpartum" we find the following recommendations:

RECOMMENDATION 52: The impact of pregnancy on women with medullary carcinoma is unknown. Surgery is recommended during pregnancy in the presence of a large primary tumour or extensive lymph node metastases.

As with the general population, the routine measurement of calcitonin remains controversial. Calcitonin measurement should be performed in pregnant women with a family history of medullary thyroid carcinoma or MEN 2. However, the utility of measuring calcitonin in all pregnant women with thyroid nodules has not been evaluated in the literature.

RECOMMENDATION 47: The utility of measuring calcitonin in pregnant women with thyroid nodules is unknown [3].

\section{Materials and Methods}

We present the case of a 28-year-old female, with history of MEN2A syndrome confirmed by genetic screening and manifested by bilateral pheochromocytoma, for which she underwent right adrenalectomy in 2009 and left adrenalectomy in 2011, as well as by medullary carcinoma of the thyroid, for which total thyroidectomy was performed in 2009. At present, the patient is under replacement treatment of the thyroid function with LT4 (Euthyrox $125 \mathrm{mcg} /$ day) and glucocorticoid and mineralocorticoid replacement therapy with Prednisone $10 \mathrm{mg} /$ day and Astonin 1 tablet / day. Currently, the patient has been periodically presenting herself for clinical and therapeutic endocrinological re-evaluation, in the context of an ongoing pregnancy.
During a presentation, in September 2015, the pregnancy being in its 24th week, a possible remnant of thyroid tissue was detected by anterior neck ultrasound exam in the left thyroid lodge, described as a solid hypoechoic image, approximately $6.6 / 4 / 5.4 \mathrm{~mm}$, with discreet vascularization (Figures 1-4). This ultrasound aspect was described at previous presentations as well, but the previous admission (July 2015) did not also detect the presence of a $9.8 / 5.2$ $\mathrm{mm}$ superior and mediolateral adenopathy, well defined, with some interior calcifications, discretely vascularized, and therefore of a suspicious nature. A left supraclavicular small cluster of microcalcifications was also detected, with a diameter of $3.2 \mathrm{~mm}$, without ultrasound evidence of its inclusion within an adenopathy, and pretracheal and to the right a group of calcifications of 5.4 / 4 / $5.6 \mathrm{~mm}$ was described, possibly located within a lymphadenopathy, these microcalcifications bearing equivocal ultrasound appearance.

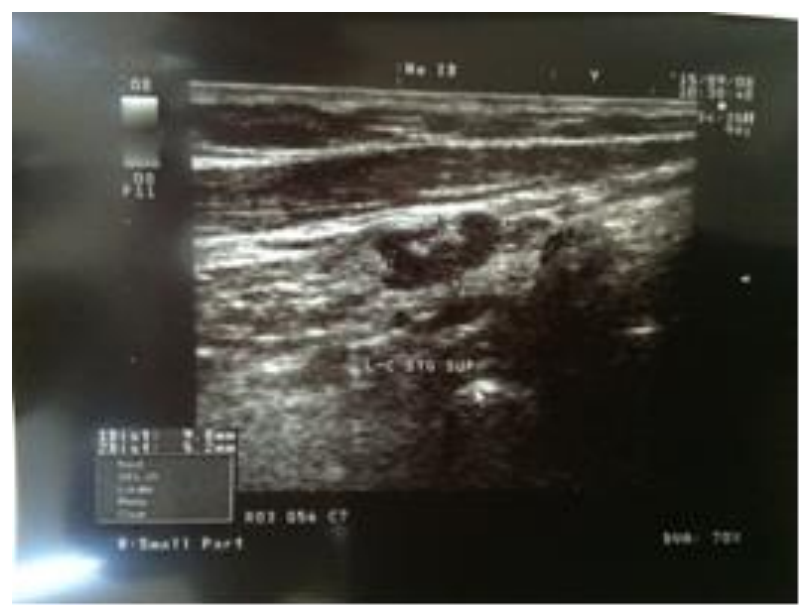

Figure 1 - Echographic aspect of anterior cervical region in September 2015 (a)

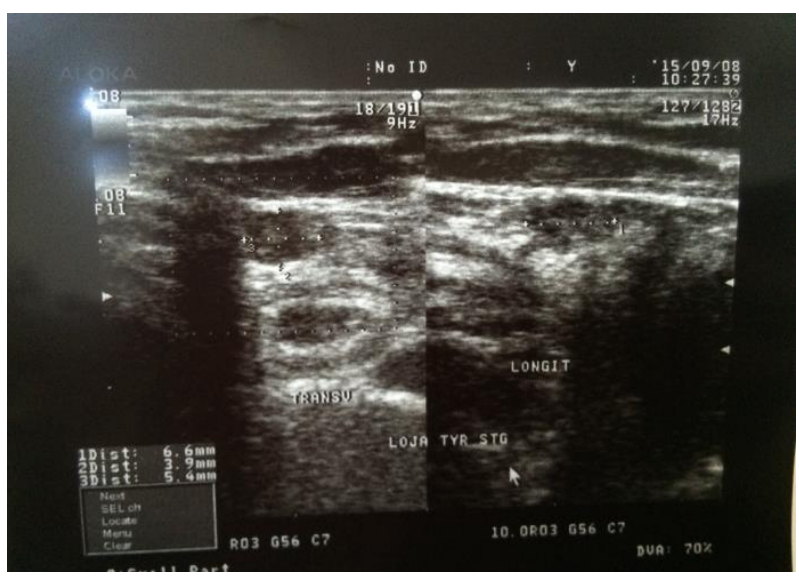

Figure 2 - Echographic aspect of anterior cervical region in September 2015 (b) 


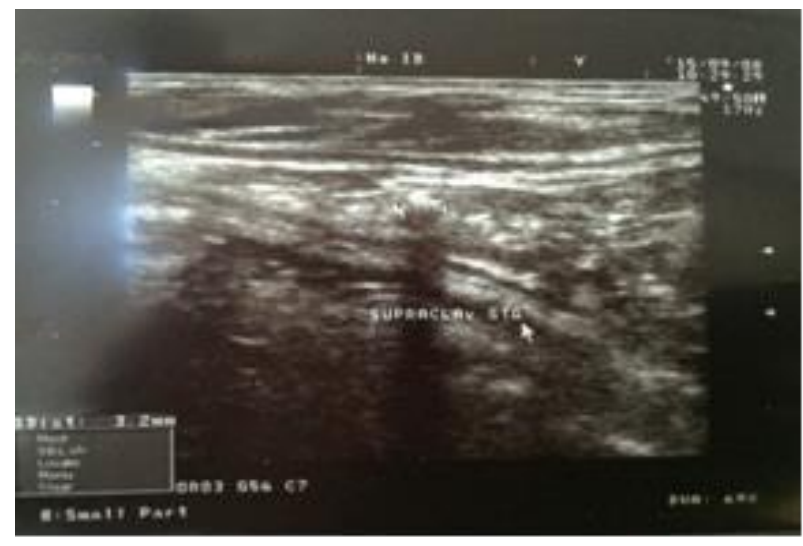

Figure 3 - Echographic aspect of anterior cervical region in September 2015 (c)

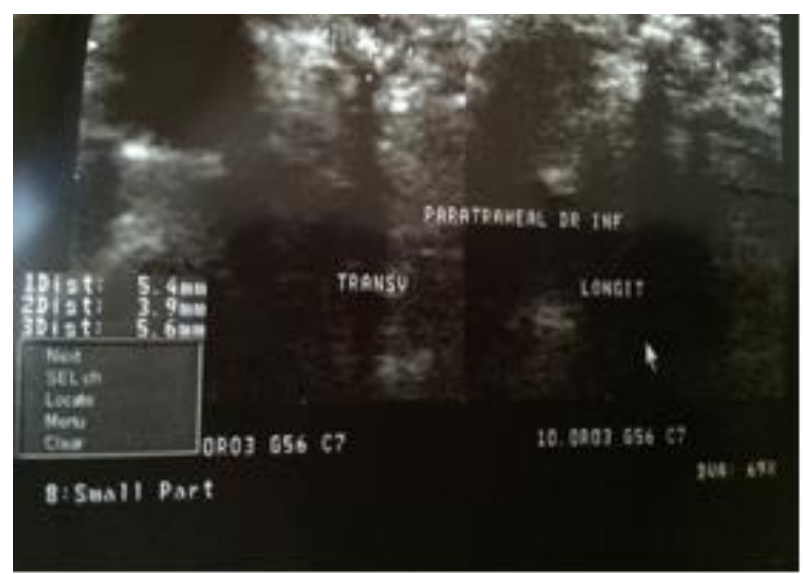

Figure 4 - Echographic aspect of anterior cervical region in September 2015 (d)

Calcitonin blood level was measured in order to dynamically correlate its evolution with the new ultrasound findings. On 14/07/2015 it had a value of $40.20 \mathrm{pg} / \mathrm{ml}$, with a significant increase at the current dosing on 17/09/2015, reaching $587.20 \mathrm{pg} / \mathrm{ml}$.

Another important aspect is that during hospitalization in July 2015, the TSH level was at the inferior normal limit, while in September it was 4.13 micro / $\mathrm{ml}$, with thyroid hormone levels being within normal range in both cases.

Currently (october 2015): the TSH level is $1,30 \mathrm{microUI} / \mathrm{ml}$, and the anterior neck ultrasound exam describes a possible remnant of thyroid tissue in the left thyroid lodge with an obvious suspect character and cervical microcalcifications with equivocal ultrasound aspect; the anterolateral adenopathy with calcifications is clearly described.

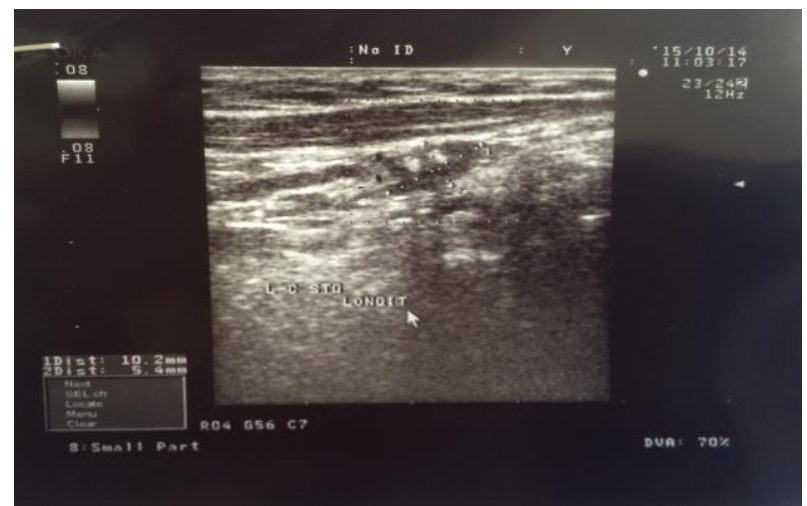

Figure 5 - Echographic aspect of anterior cervical region in October 2015 (a)

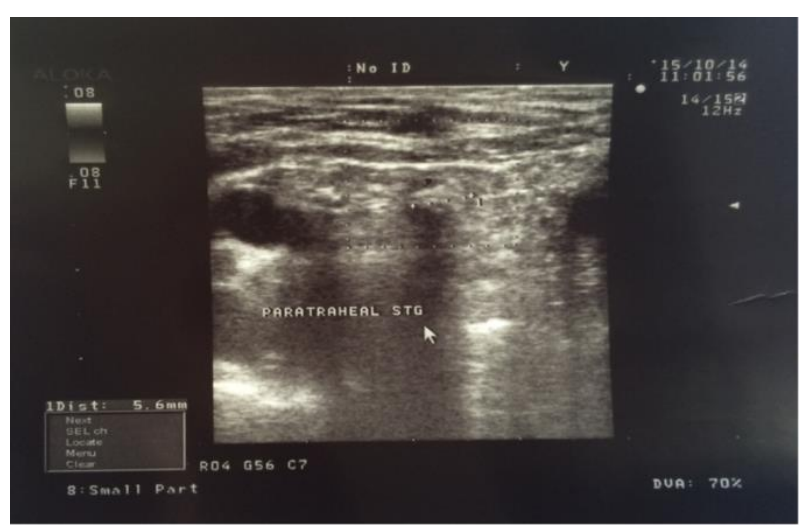

Figure 6 - Echographic aspect of anterior cervical region in October 2015 (b)

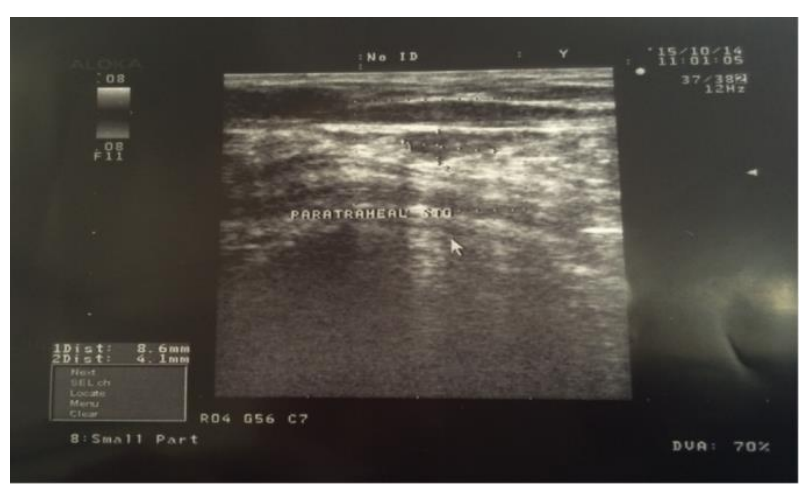

Figure 7 - Echographic aspect of anterior cervical region in October 2015 (c)

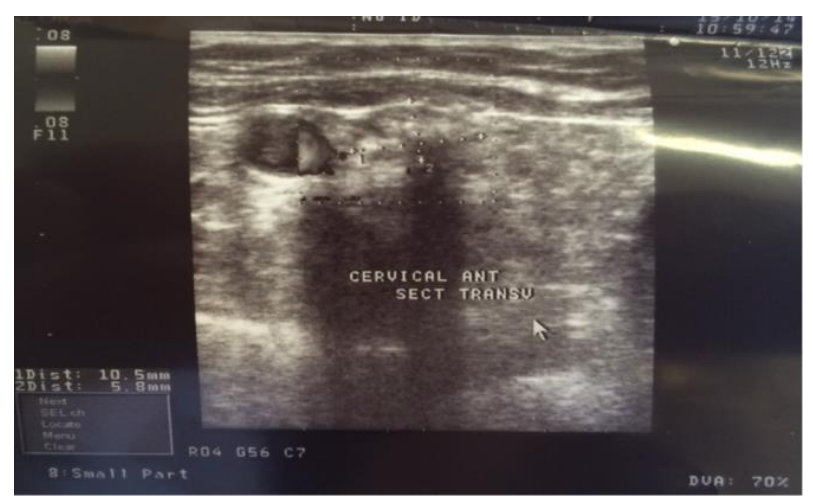

Figure 8 - Echographic aspect of anterior cervical region in October 2015 (d) 
The patient refused surgery. She was informed of the risks of recurrence of thyroid carcinoma during pregnancy, as well as of the risk of fetal harm due to the presence of RET proto-oncogene mutations. Delay of treatment and endocrinological follow-up within one month were decided for.

\section{Discussions}

In the cases of pregnant women known with MEN2 syndrome or medullary thyroid carcinoma medical history for which they underwent surgical interventions, adrenalectomy or total thyroidectomy and that have recurrence during pregnancy of thyroid tumour, there is no standardized therapeutic attitude and the impact over pregnancy is also not known. However, the surgical intervention in case of extensive ganglionar metastasis and in case of primary medullary carcinoma of the thyroid is recommended.

Our decision was to delay the surgical intervention during pregnancy with periodic clinical and paraclinical follow-up, with periodic thyroid ultrasound examination and calcitonin dosing. Postnatally, the surgical intervention will be performed.

\section{Conclusions}

We present the case of a 28-year-old female with history of MEN 2A syndrome, who, in the context of an ongoing pregnancy (24 weeks at the last presentation), presents regularly for clinical and therapeutic endocrinological reevaluation. In this context, during the last admission, a suspicious left laterocervical lymphadenopathy with numerous microcalcifications of equivocal appearance was detected by anterior cervical ultrasound. Elevated serum calcitonin value, supporting the suspicion of a medullary thyroid carcinoma recurrence, and elevated TSH value were also found. Treatment of the patient is currently delayed, as she is refusing surgery for the moment.

\section{References}

[1]Moline J, "Multiple endocrine neoplasia type 2: an overview", Eng C. (2011).

[2]Thosani S, Ayala-Ramirez M, Palmer L, Hu MI, Rich T, Gagel RF, Cote G, Waguespack SG, Habra MA, Jimenez C (2013) The characterization of pheochromocytoma and its impact on overall survival in Multiple Endocrine Neoplasia type 2. J Clin Endocrinol Metab.

[3]Stagnaro-Gree A, Abalovich M, Alexander E, Azizi F, Mestman J, Negro R, Nixon A, Pearce E.N, Soldin O.P, Sullivan S, and Wiersinga W, Guidelines of the American Thyroid Association for the Diagnosis and Management of Thyroid Disease During Pregnancy and Postpartum. Available from: http://www.thyca. org/download/document/486/PregnancyandPostpart um.pdf 